\title{
Mensuração da Eficiência Bancária no Brasil - A Inclusão de Indicadores Macroprudenciais
}

\author{
Cláudio Ruiz* \\ Benjamin M. Tabak** \\ Daniel O. Cajueiro***
}

\begin{abstract}
Resumo
O cálculo da eficiência bancária tem sido objeto de muitos estudos acadêmicos nos últimos anos, em várias partes do mundo. As variáveis comumente utilizadas para a medição da eficiência bancária provêm de dados relativos à administração das instituições e informações extraídas de documentos contábeis. Diferentemente, neste estudo investigou-se a eficiência bancária no Brasil, utilizando dados relativos ao período compreendido entre 1995 e 2005, aplicando-se a metodologia de fronteira estocástica de custo, adicionando indicadores macroprudenciais àquelas variáveis comumente encontradas na literatura. Os resultados do estudo sugerem que indicadores macroprudenciais contribuem tanto para a estimação da fronteira de custo quanto para o cálculo da eficiência bancária.
\end{abstract}

Palavras-chave: indicadores macroprudenciais; eficiência bancária; fronteira estocástica.

Códigos JEL: G21.

Abstract

The measure of bank efficiency has been object of many studies in the past years, in several parts of the world. The variables that are frequently used to measure bank efficiency are relative to the administration of institutions and are extracted from accounting data. Differently, this study focuses on Brazilian bank efficiency, using data from 1995 to 2005, applying a stochastic frontier methodology and including macro-prudential indicators. The results of the paper suggest that macro-prudential indicators contribute to the estimation of the cost frontier and to the measurement of bank efficiency.

Keywords: macro-prudential indicators; bank efficiency; stochastic frontier.

Submetido em Junho de 2007. Aceito em Agosto de 2008. O artigo foi avaliado segundo o processo de duplo anonimato além se de ser avaliado pelo editor. Editor responsável: Marcelo Medeiros. Os autores agradecem a dois pareceristas anônimos pelas sugestões que foram importantes para aprimorar o artigo. As opiniões expressas neste artigo são de responsabilidade dos autores e não necessariamente representam as opiniões do Banco Central do Brasil. Benjamin M. Tabak e Daniel O. Cajueiro agradecem ao CNPq pelas bolsas de pesquisa.

*Banco Central do Brasil. E-mail: claudio.ruiz@bcb.gov.br

**Univ. Católica de Brasília e Banco Central do Brasil. E-mail: benjamin.tabak@bcb.gov.br

*** Univ. de Brasília. E-mail: danielcajueiro@ gmail.com 


\section{Introdução}

A eficiência bancária tem sido objeto de estudos acadêmicos por muitos anos. Enquanto a grande maioria dos estudos foi baseada em dados norte-americanos, recentemente os pesquisadores começaram a verificar os padrões da eficiência bancária em outros países, inclusive aqueles ainda em desenvolvimento.

No Brasil, a implantação do Plano Real, ocorrida no segundo semestre de 1994, levou à estabilização da economia e a um conjunto de medidas com o objetivo de fortalecer o sistema financeiro. Essa nova realidade fez surgir a necessidade de uma maior eficiência por parte das instituições financeiras, de modo a compensar a queda dos ganhos elevados recebidos durante os anos de alta inflação. A queda significativa da inflação cessou os ganhos bancários derivados das receitas inflacionárias, revelando a fragilidade do sistema, obrigando o Banco Central a intervir em diversos bancos, originando ainda várias liquidações no setor bancário.

Esse artigo tem como objetivo calcular a ineficiência bancária no Brasil e determinar as características que a influenciam, considerando além das variáveis usualmente encontradas na literatura, alguns indicadores de solidez financeira, também chamados de macroprudenciais, ${ }^{1}$ o que nos permite responder à seguinte pergunta: Características macroprudenciais influenciam a ineficiência bancária?

Como subproduto desse estudo, podemos ainda comparar bancos nacionais e estrangeiros, públicos e privados em termos de eficiência e determinar que tipos de indicadores os órgãos supervisores devem monitorar para identificar indícios de futuros problemas na saúde do Sistema Financeiro Nacional. ${ }^{2}$

Para tanto, utilizamos dados que se iniciam no segundo semestre de 1995. Essa janela de tempo é interessante, pois inclui uma série de fatos relevantes como, por exemplo, o estabelecimento de incentivos fiscais para a incorporação de instituições financeiras, a instituição do Programa de Estímulo à Reestruturação e ao Fortalecimento do Sistema Financeiro Nacional - PROER, a regulamentação do Fundo Garantidor de Créditos - FGC e o incentivo ao processo de fusão, incorporação e transferência de controle acionário (Silva e Jorge Neto, 2002).

Perseguindo esses objetivos, incluímos em nossa base de dados características macroeconômicas com o intuito de identificar algumas variáveis relevantes para a aferição da saúde do Sistema Financeiro Nacional, de modo que essas variáveis possam ser entendidas como indicadores macroprudenciais.

A seguir, estimamos a eficiência bancária no Brasil, no período decorrido entre 1995 e 2005, utilizando a fronteira estocástica de custo. Finalmente, verificamos os indicadores associados à ineficiência existente no sistema.

\footnotetext{
${ }^{1}$ De acordo com o FMI (Financial Soundness Indicators: Policy Paper, 2001), não há definição aceita universalmente de indicadores de solidez financeira, ou macroprudenciais. As definições existentes incluem todos os indicadores possíveis relacionados à solidez do sistema financeiro, incluindo indicadores macroeconômicos relevantes, como taxas de câmbio e juros, e indicadores de mercado, como preços de ações de instituições financeiras, spreads e classificações de crédito.

${ }^{2} \mathrm{O}$ painel é não balanceado. Assim, bancos que foram adquiridos saem da amostra e entram nos balanços dos bancos adquirentes. As variáveis de controle acionário seguiram o padrão definido pelo Banco Central do Brasil.
} 
O restante deste artigo está organizado da seguinte forma: na seção 2, apresentamos uma revisão da literatura que aborda alguns estudos prévios relacionados aos estudos ora efetuados. Na seção 3, discutimos a metodologia empregada. $\mathrm{Na}$ seção 4, descrevemos como foi criada a base de dados utilizada, enquanto nas seções 5 e 6, respectivamente, apresentamos os resultados e as conclusões.

\section{Revisão Bibliográfica}

A revisão bibliográfica encontra-se dividida em quatro seções: na primeira, analisamos alguns trabalhos importantes para o desenvolvimento da metodologia de fronteira estocástica; na segunda, são mencionados vários estudos relacionados com a eficiência bancária; na terceira, citamos outros estudos, relacionados com o sistema bancário brasileiro; na quarta seção, concluímos esse capítulo com um resumo sobre os principais aspectos de toda a literatura apresentada.

\subsection{Metodologia de fronteira estocástica}

Farrell (1957) propôs uma medida de eficiência de uma firma, que consiste de dois componentes: "eficiência técnica", que reflete a habilidade de uma firma de obter máxima produção dada uma determinada quantidade de insumos, e "eficiência alocativa", que reflete a habilidade de uma firma para usar os insumos em proporções ótimas, dados seus respectivos preços. Essas duas medidas combinadas proporcionam uma medida de "eficiência econômica" total.

Essa eficiência assume que a função de produção absolutamente eficiente da firma é conhecida. Uma vez que essa função de produção nunca é conhecida na prática, Farrell (1957) sugeriu que essa função seja estimada a partir de dados amostrais usando, por exemplo, uma função da forma Cobb-Douglas. A partir dessa sugestão, alguns modelos foram testados, resultando no desenvolvimento da metodologia de fronteira estocástica.

Aigner e Chu (1968) estimaram uma função da fronteira de produção na forma Cobb-Douglas, usando dados de uma amostra de $N$ firmas, sendo o modelo definido como

$$
\ln \left(y_{i}\right)=x_{i} \beta-u_{i}, i=1,2, \ldots N
$$

onde $u_{i}$ é uma variável randômica não-negativa, associada à ineficiência técnica produtiva das firmas do setor envolvido.

A razão do produto observado para a i-ésima firma, relativamente ao produto potencial, definido pela fronteira de produção, dado um vetor de insumos $x_{i}$, é usada para definir a eficiência técnica da i-ésima firma:

$$
T E_{i}=\frac{y_{i}}{\exp \left(x_{i} \beta\right)}=\frac{\exp \left(x_{i} \beta-u_{i}\right)}{\exp \left(x_{i} \beta\right)}=\exp \left(-u_{i}\right)
$$

Esta medida recebe um valor entre 0 e 1 e indica a magnitude do produto da i-ésima firma relativamente ao produto que poderia ser produzido por uma firma totalmente eficiente. 
Aigner et alii (1977) e Meeusen e Van Den Broeck (1977) propuseram, ao mesmo tempo e independentemente, a função da fronteira de produção estocástica, na qual um erro aleatório adicional, $v_{i}$, é adicionado à variável aleatória $u_{i}$, obtendo-se

$$
\ln \left(y_{i}\right)=\mathrm{x}_{i} \beta+v_{i}-u_{i}, i=1,2, \ldots N
$$

$\mathrm{O}$ erro aleatório $v_{i}$ representa erros de medida e outros fatores aleatórios, tais como, clima, sorte, etc.

Aigner et alii (1977) assumiram que os $v_{i}$ eram variáveis aleatórias independentes e identicamente distribuídas (i.i.d.) com média zero e variância constante, sendo ainda independentes dos $u_{i}$, que seriam variáveis aleatórias i.i.d. exponenciais ou meio-normais.

Esse modelo é chamado de função da fronteira de produção estocástica, pois os valores de produto são limitados acima pela variável estocástica $\exp \left(x_{i} \beta+v_{i}\right)$. $\mathrm{O}$ erro aleatório $v_{i}$ pode ser positivo ou negativo e assim os produtos da fronteira estocástica variam ao redor da parte determinística do modelo da fronteira, $\exp \left(x_{i} \beta\right)$.

Da mesma forma, se quisermos calcular a função de uma fronteira de custo de produção, basta adicionar os $u_{i}$ ao invés de subtraí-los. Isso porque a função de custo representa mínimo custo, enquanto a função de produção representa máximo produto.

A equação de custo fica, então,

$$
\ln \left(y_{i}\right)=\mathrm{x}_{i} \beta+v_{i}+u_{i}, i=1,2 \ldots n
$$

Os $u_{i}$ nos dão informação sobre o nível de eficiência no custo da i-ésima firma, que será calculada como

$$
C E_{i}=\frac{\exp \left(x_{i} \beta\right)}{y_{i}}=\frac{\exp \left(x_{i} \beta\right)}{\exp \left(x_{i} \beta+u_{i}\right)}=\exp \left(-u_{i}\right)
$$

Alguns estudos, por exemplo Pitt e Lee (1981) e Kalirajan (1981) investigaram os determinantes de ineficiências técnicas entre firmas de um mesmo setor, regredindo os efeitos da ineficiência encontrados, obtidos a partir de uma fronteira estocástica estimada, sobre um vetor de fatores específicos para cada firma, tais como tamanho, idade, educação dos diretores, etc, numa análise de segundo estágio.

Entretanto, foi se encontrado um problema significativo com esse estudo em dois estágios. Os efeitos da ineficiência deveriam ser i.i.d. para se usar Jondrow et alii (1982) e predizer os valores dos efeitos da ineficiência técnica. Entretanto, no segundo estágio, os efeitos da ineficiência encontrados são uma função de um número de fatores específicos para cada firma, o que implica que eles não são i.i.d., a menos que todos os coeficientes dos fatores sejam zero, simultaneamente.

Kumbhakar et alii (1991) e Reifschneider e Stevenson (1991) notaram essa inconsistência e especificaram modelos de fronteira estocástica nos quais os efeitos 
da ineficiência eram definidos como funções de alguns dos fatores específicos e todos os parâmetros eram estimados em um procedimento de máxima verossimilhança em um único estágio.

Huang e Liu (1994) também apresentaram um modelo para uma função de produção da fronteira estocástica, no qual os efeitos da ineficiência técnica eram especificados como uma função de alguns fatores específicos, conjuntamente com suas interações com as variáveis de insumo da função da fronteira.

Battese e Coelli (1995) estenderam esses estudos, utilizando dados em formato de painel, permitindo estimar os parâmetros dos fatores que se acreditam influenciarem os níveis de eficiência técnica, juntamente com os componentes relativos à mudança na ineficiência técnica. A especificação deste modelo está descrita em Coelli et alii (1998) e encontra-se implementada no programa Frontier.

Todas essas propostas deram base a vários estudos econométricos, que passaram a examinar eficiência de custo e lucro. Podemos citar, entre eles, Berg et alii (1993), Fecher e Pestieau (1993), Ruthenberg e Elias (1996), Allen e Rai (2000), Hughes et alii (1996), Pastor et alii (1997), Berger e Humphrey (1997), Dietsch e Lozano-Vivas (2000) e Maudos et alii (2002).

Berger e Humphrey (1997) concluíram que fronteira eficiente parece superior à análise financeira tradicional para medir performance. Ainda de acordo com eles, estudos de eficiência bancária contribuem para a política governamental, pesquisa e administração bancária.

\subsection{Eficiência bancária}

Nos últimos anos, muitos estudos têm sido feitos de modo a se examinar o que leva um banco a obter uma melhor eficiência em relação aos demais. Dentre esses estudos, uma grande quantidade tem se preocupado com a origem do capital dessas instituições.

Nos Estados Unidos, vários estudos mostraram que os bancos estrangeiros são menos eficientes que os domésticos: Hasan e Hunter (1996), Mahajan et alii (1996), DeYoung e Nolle (1996), Chang et alii (1998), Peek et alii (1999). Na Europa, essa evidência foi encontrada por Yildrin e Philippatos (2002).

Por outro lado, na América Latina, a evidência encontrada é mista. Enquanto Barajas et alii (2000) encontraram que bancos estrangeiros são mais produtivos que os domésticos, Crystal et alii (2001) viram pouca diferença entre essas duas classes de bancos.

Um estudo realizado por Claessens et alii (2001), contendo observações de 80 países, no período compreendido entre 1988 e 1995, encontrou bancos estrangeiros em nações desenvolvidas menos lucrativos que os bancos domésticos, ocorrendo o contrário nas nações em desenvolvimento.

Berger et alii (2000) propuseram duas hipóteses para explicar esses resultados: a hipótese de estar em casa e a hipótese da vantagem global. De acordo com a primeira hipótese, a vantagem das instituições domésticas está nos custos maiores das instituições estrangeiras, o chamado passivo estrangeiro. A segunda 
hipótese pode ser analisada de duas formas: a geral e a limitada. Na forma geral, os bancos eficientes estrangeiros de uma gama de nações são capazes de oferecer eficiência superior quando comparados aos bancos domésticos, hipótese essa rejeitada pela literatura no momento. Na forma limitada, apenas bancos estrangeiros de um particular conjunto de nações, por obter condições favoráveis em seus países de origem, são mais eficientes que bancos domésticos. Ou seja, alguns bancos estrangeiros eficientes são capazes de superar as desvantagens advindas do passivo estrangeiro. Os estudos de Berger et alii (2000) concluíram que bancos domésticos podem ser mais eficientes que bancos estrangeiros na maioria dos países, pode estar em estado de igualdade em alguns países e podem ser menos eficientes que bancos estrangeiros americanos.

Sturm e Williams (2004) consideram o impacto da entrada de bancos estrangeiros na eficiência bancária na Austrália, chegando à conclusão de que embora os bancos estrangeiros sejam mais eficientes que os domésticos, isso não resulta em maiores lucros desses bancos.

Sensarma (2006) estimou a fronteira de eficiência dos bancos indianos, utilizando dados de 1986 a 2000, com a finalidade de comparar bancos estrangeiros, públicos e nacionais numa economia em desenvolvimento. Como resultado, foi verificado que os bancos públicos superaram os privados em matéria de eficiência, que, por sua vez, superaram os bancos estrangeiros.

Analisando bancos alemães, no período entre 1989 e 1996, a ineficiência mensurada por Altunbas et alii (2001b) indicou que os bancos públicos tiveram vantagens sobre os privados. Já no leste europeu, utilizando amostra de seis países com dados entre 1994 e 2002, Bonin et alii (2005) concluíram que os bancos estrangeiros foram mais eficientes que os bancos públicos.

Outro ponto de destaque existente na literatura é a averiguação sobre o fato de o tamanho das instituições induzir maior ou menor eficiência no sistema bancário. Um estudo efetuado por Sheldon (1999) indicou que, na Comunidade Européia, Noruega e Suíça, grandes bancos, bancos especializados e bancos de varejo são mais eficientes que bancos pequenos, diversificados e de atacado. Bos e Kool (2001), em estudo efetuado com bancos holandeses, encontraram como resultado que grandes bancos superam pequenos em termos de eficiência.

O estudo de Christopoulos et alii (2002) calcula eficiência dos bancos na Grécia entre 1993 e 1998, chegando à conclusão de que grandes bancos são menos eficientes que os menores e que empréstimos e investimentos estão positivamente relacionados à eficiência em custos. Kwan (2001) investiga eficiência dos bancos comerciais em Hong Kong, encontrando que grandes bancos são menos eficientes que pequenos bancos. Por outro lado, bancos com maior quantidade de empréstimos e depósitos são mais eficientes.

Carvallo e Kasman (2005) estimaram uma fronteira de custo para 481 bancos de 16 países da América Latina e Caribe, no período entre 1995 e 1999, verificando existir muitas diferenças entre eles. Sua análise identificou que os maiores e os menores eram mais eficientes que os demais. Além disso, encontraram indícios 
de que bancos com maiores ativos totais têm menor nível de eficiência. Bancos com maior volume de empréstimos também mostraram maior eficiência, o mesmo ocorrendo com os bancos com maior proporção de depósitos/ativo. Já a relação custo/ativo mostrou correlação com ineficiência. Ainda foi verificado que bancos com maior quantidade de empréstimos inadimplentes se mostraram mais ineficientes.

O estudo de Halkos e Salamouris (2004) explora a eficiência dos bancos da Grécia entre 1997 e 1999, caracterizando que a eficiência aumenta com o aumento dos ativos totais e que o crescimento da eficiência no período foi acompanhado por uma redução de bancos pequenos, causada por fusões e aquisições.

Schure et alii (2004) calcularam a eficiência do setor bancário europeu entre 1993 e 1997, verificando que houve diminuição do custo com o aumento da concorrência. Além disso, foi visto que os grandes bancos comerciais controlaram mais os custos que os pequenos, não valendo o mesmo raciocínio para os bancos de poupança.

Quanto ao grau ideal de participação de capital de terceiros nas instituições, Berger e Humphrey (1997) mencionam que o risco de insolvência de um banco depende do capital financeiro disponível para absorver perdas em seu portfólio. Como primeiro efeito, os juros pagos sobre dívidas contam como custo, o que não ocorre com os dividendos. Como segundo efeito, o aumento de capital envolve maiores custos que o aumento dos depósitos. Se o primeiro efeito dominar, os custos medidos serão maiores para os bancos com alta proporção de dívidas financiadas; se o segundo efeito dominar, os custos mensurados serão menores para estes bancos.

Estrada e Osorio (2004), usando fronteira estocástica para análise da eficiência dos bancos colombianos entre 1989 e 2003, concluíram que o capital financeiro está positivamente correlacionado com o custo total.

O estudo de Altunbas et alii (2000) calcula eficiência nos bancos comerciais japoneses entre 1993 e 1996, revelando que o nível de capital financeiro influencia significativamente a eficiência e a determinação do tamanho ótimo de um banco.

Altunbas et alii (2001b) estimaram economia de escala, ineficiências administrativas e mudança técnica para uma grande amostra de bancos europeus entre 1989 e 1997, obtendo como resultado que a maior parte do benefício colhido pelas maiores instituições adveio do progresso técnico. Foi ainda relatado que bancos de todos os tamanhos podem obter maior corte de custos reduzindo ineficiências administrativas.

Drake e Hall (2003) analisaram eficiência nos bancos japoneses, indicando que os maiores bancos geralmente apresentaram oportunidade de ganho limitado na eliminação de ineficiências administrativas, com o contrário sendo esperado em relação aos bancos menores. Além disso, os resultados sugeriram a necessidade de controle do impacto exógeno de empréstimos problemáticos, especialmente para os menores bancos regionais.

Prior (2003) analisou bancos espanhóis de poupança entre 1986 e 1995, iden- 
tificando que a maior parte da ineficiência encontrada foi estrutural e dependente do tamanho da rede de agências. O aumento da rede de agências reduziu o nível de utilização de sua capacidade, gerando ineficiências de custo.

Canhoto e Dermine (2003) calcularam a eficiência em Portugal entre 1990 e 1995, apontando que a desregulamentação foi seguida por aumento de eficiência. O estudo mostrou que mudanças em um sistema bancário antes represado geraram um aumento da eficiência depois de sua liberação. Os novos bancos tiveram vantagens em relação aos velhos por não estarem vinculados ao passado e podendo escolher entre as melhores técnicas existentes no mercado, aumentando a competição.

Bos e Kool (2006), utilizando dados de 401 bancos cooperativos da Holanda, no período entre 1998 e 1999, obtiveram como resultado que a maior parte da ineficiência estimada foi de cunho administrativo, sendo que fatores ambientais se mostraram causadores de ineficiência, porém com um poder bastante reduzido.

Quanto aos valores encontrados de eficiência, foi verificado que eles diferem sobremaneira, não só por conta da diferença existente entre os países e a época examinada, mas também por conta do modo de cálculo. Foram encontrados valores dispersos entre $49,6 \%$ e $96 \%$.

\subsection{Sistema bancário brasileiro}

Nakane (1999), analisando dados de 1990 a 1997, concluiu que, enquanto a inflação possui efeito negativo, o tamanho e o volume dos empréstimos impactam positivamente a eficiência. Além disso, os bancos públicos se mostraram mais eficientes que os privados e os bancos estrangeiros foram mais eficientes que os de controle nacional, no período estudado.

Silva e Jorge Neto (2002), utilizando dados de bancos com ativo acima de 1 bilhão de reais, estimaram uma fronteira estocástica de custo translog, para o período compreendido entre 1995 e 1999, e obtiveram os seguintes resultados: os bancos pequenos e grandes foram mais eficientes em relação às instituições de porte mediano; a razão de capital próprio sobre o ativo total possui uma correlação positiva com eficiência; a qualidade dos créditos apresentou impacto negativo sobre eficiência do setor, embora não significativo; bancos que utilizam amplamente empréstimos e repasses governamentais para financiar seu ativos são menos eficientes; quanto maior a proporção de depósitos à vista em relação aos depósitos totais, menor a eficiência da firma; os bancos públicos se mostraram mais ineficientes que os particulares, enquanto os bancos estrangeiros foram mais eficientes que os nacionais.

Krause e Tabak (2004), analisando dados de bancos comerciais relativos ao período de 1995 a 2003, com o uso da metodologia DEA, concluíram, dentre outras coisas, que os bancos com controle privado foram mais eficientes que os bancos com controle público. 
Nakane e Weintraub (2005), utilizando dados de 1990 a 2002, seguindo a metodologia proposta por Levinsohn e Petrin (2003), obtiveram como resultado que os bancos públicos foram menos produtivos que os privados.

Analisando as privatizações e reestruturações ocorridas nos bancos públicos brasileiros na década de 1990, Beck et alii (2005) concluíram que os bancos privatizados melhoraram sua performance, enquanto que os reestruturados não o fizeram.

Quanto aos valores encontrados de eficiência, foi verificado que eles diferem sobremaneira, não só por conta da diferença existente entre na época examinada, mas também por conta do modo de cálculo. Foram encontrados valores dispersos entre $44 \%$ e $89 \%$.

\subsection{Resumo da literatura estudada}

Em resumo, podemos identificar que existe um número grande de métodos para se mensurar eficiência, que nem sempre levam à mesma conclusão.

Instituições de diferentes países possuem graus variados de eficiência e que mudam ao longo do tempo, seja por atitudes governamentais, seja por aumento da competitividade do mercado, seja por mudanças na administração das próprias instituições.

Não fica claro se a eficiência bancária em países emergentes é maior ou menor que em países desenvolvidos, nem tampouco quais são os fatores que explicam essa eficiência.

Enquanto alguns estudos mostraram que os bancos estrangeiros são menos eficientes que os domésticos - Hasan e Hunter (1996), Mahajan et alii (1996), DeYoung e Nolle (1996), Chang et alii (1998), Peek et alii (1999), Yildrin e Philippatos (2002) e Sensarma (2006) -, outros encontraram resultados contrários Silva e Jorge Neto (2002), Barajas et alii (2000), Sturm e Williams (2004) e Bonin et alii (2005) -, enquanto que o estudo de Claessens et alii (2001) obteve resultados opostos para as nações desenvolvidas e em desenvolvimento e o estudo de Crystal et alii (2001) não mostrou diferenças entre os bancos estrangeiros e domésticos.

Da mesma forma, foram encontrados resultados opostos no tocante à eficiência dos bancos públicos e privados. Enquanto os estudos de Sensarma (2006), Altunbas et alii (2001b) e Nakane (1999) indicaram vantagens para os bancos públicos, os estudos de Silva e Jorge Neto (2002), Krause e Tabak (2004) e Nakane e Weintraub (2005) mostraram vantagens para os bancos privados.

Quanto ao tamanho das instituições, enquanto Sheldon (1999) e Bos e Kool (2001) verificaram que os grandes bancos eram mais eficientes que os pequenos, Christopoulos et alii (2002) e Kwan (2001) encontraram o contrário. Já Carvallo e Kasman (2005) e Silva e Jorge Neto (2002) concluíram que os maiores e os menores eram mais eficientes que os demais.

Finalmente, na revisão bibliográfica empreendida, identificamos a quase inexistência de estudos relacionando indicadores macroprudenciais à eficiência bancária. 


\section{Metodologia}

Existe desvantagem na utilização de modelos de regressão quando se estuda performance bancária, pois tais modelos assumem que todos os bancos são igualmente eficientes, o que vem a ser uma restrição bastante forte. Neste estudo, empregamos o método paramétrico de análise da fronteira estocástica, em vista de sua capacidade em determinar erros e da possibilidade de identificar diversos fatores que podem estar causando esses erros.

Utilizamos a metodologia de Battese e Coelli (1995) pelas várias vantagens que oferece quando comparada às metodologias tradicionais. Ela permite estimação simultânea da função da fronteira e da função de ineficiência em um único procedimento de máxima verossimilhança, que evita os problemas teóricos dos trabalhos efetuados em duas etapas.

Assumindo que o objetivo é minimizar custos, a fronteira de custo baseada em dados em forma de painel pode ser representada como:

$$
C_{i t}=f\left(y_{i t}, p_{i t}\right)+v_{i t}+u_{i t}
$$

onde $i$ representa a instituição;

$t$ representa o tempo;

$C$ é a variável custo;

$y$ é o vetor de produtos; $\mathrm{e}$

$p$ o vetor de preços, todas as variáveis medidas em logaritmos. O erro $v_{i t} \sim$ $i i d N\left(0, \sigma_{v}^{2}\right)$ e o fator de ineficiência $u_{i t}$ é não negativo, com distribuição truncada $N\left(\mu_{i t}, \sigma^{2}\right)$, onde $\mu_{i t}=Z_{i t} \delta$. O modelo de ineficiência é então especificado como:

$$
u_{i t}=Z_{i t} \delta+\epsilon_{i t}
$$

onde $z_{i t}$ é um vetor de variáveis observáveis explicativas da ineficiência de uma firma e $\delta$ é um vetor de parâmetros escalares desconhecidos a serem estimados (geralmente incluindo um intercepto).

A função de log-verossimilhança para esta fronteira estocástica é apresentada no Apêndice em Battese e Coelli (1993), juntamente com as primeiras derivadas parciais da função de log-verossimilhança com respeito aos diferentes parâmetros do modelo. Essas expressões são dadas nos termos dos parâmetros de variância $\sigma_{s}^{2}=\sigma_{v}^{2}+\sigma^{2}$ e $\gamma=\sigma^{2} / \sigma_{s}^{2}$, onde o parâmetro $\gamma$ tem valor entre zero e um.

Uma vez calculados, os $u_{i t}$ provêm informação sobre o nível de eficiência de custo $\left(C E_{i t}\right)$ da i-ésima firma no período $t$. Isto pode ser calculado como sendo a razão entre o custo mínimo na fronteira $\left(\operatorname{com} u_{i t}=0\right)$ e o custo observado, que pode ser demonstrado como sendo igual a $C E_{i t}=\exp \left(-u_{i t}\right)$.

Verificamos, a seguir, a hipótese nula de que não há efeitos de ineficiência técnica no modelo. Isso pode ser feito testando o conjunto de hipóteses $H 0: \gamma=0$ contra $H 1: \gamma>0$. Se $H 0: \gamma=0$ é verdadeiro, esta estatística é assintoticamente distribuída como uma variável aleatória normal padrão. Notemos que este teste 
tem que ser conduzido como um teste de um único lado, pois $\gamma$ não assume valores negativos.

Para tanto, o modelo é estimado sob as hipóteses nula e alternativa. Sob a hipótese nula, $H 0: \gamma=0$, o modelo equivale à regressão linear simples, sem o efeito de ineficiência técnica $u_{i}$. O teste estatístico é calculado como

$$
L R=-2\left\{\ln \left[L\left(H_{0}\right) / L\left(H_{1}\right)\right]\right\}=-2\left\{\ln \left[L\left(H_{0}\right)\right]-\ln \left[L\left(H_{1}\right)\right]\right\}
$$

onde $L\left(H_{0}\right)$ e $L\left(H_{1}\right)$ são os valores da função de verossimilhança sob as hipóteses nula e alternativa $H_{0}$ e $H_{1}$, respectivamente.

Partindo da eficiência calculada, podemos chegar a algumas conclusões no tocante a algumas variáveis utilizadas no modelo, permitindo-nos concluir se determinados índices ou mesmo dados cadastrais se relacionam positivamente ou negativamente com a eficiência das instituições.

\section{Dados e Especificações Econométricas}

Os dados relativos a demonstrações financeiras foram extraídos de 2.758 balanços semestrais entregues pelas instituições ao Banco Central do Brasil, durante o período compreendido entre dezembro de 1995 e junho de 2005, e todas as variáveis financeiras foram trazidas a valores presentes, considerando-se como data base 30.06.2005. Foram utilizados dados de 243 instituições, sendo 130 privadas exclusivamente nacionais, 27 públicas, 14 estrangeiras, 56 com controle estrangeiro e 16 com participação estrangeira.

O primeiro passo para a modelagem é decidir se depósitos são parte dos insumos ou produtos de um banco. Nós seguimos a teoria do valor adicionado (Berger e Humphrey, 1992, Grifell-Tatjé e Lovell, 1995, Berg et alii, 1993) que trata depósitos e empréstimos como produtos. Sendo assim, nosso vetor de produtos consiste de Ativos Líquidos, Depósitos e Investimentos. A variável dependente é o custo total da instituição no período. Tanto os produtos quanto a variável dependente foram normalizados, dividindo-os pelo total de empréstimos existentes no ativo da instituição. O vetor de preços possui apenas uma variável, construída como sendo a razão entre o preço do capital e o preço dos depósitos, de modo que a especificação assumisse homogeneidade com respeito aos preços. Para tanto, também a variável dependente foi dividida pelo preço dos depósitos.

No nosso caso, na equação (6), $C$ é o custo total da instituição, $y$ é o vetor de produtos constituídos pelo total do ativo líquido, investimentos e depósitos efetuados no período e $p$ é o vetor de preços constituído pela variável preço do capital/preço dos depósitos. A essa equação foi incluído ainda um vetor $x$ de indicadores macroprudenciais, constituído pela taxa média de juros no semestre, representada pelo C-Bond no período, e a volatilidade média do índice Ibovespa.

Para o cálculo do modelo de ineficiência, na equação (7), o vetor $z$ incluiu variáveis dummys para instituições públicas, estrangeiras, com controle estrangeiro e com participação estrangeira, variáveis contínuas indicando o aprovisio- 
namento para créditos de liquidação duvidosa, a participação de mercado da instituição no tocante aos depósitos existentes no Sistema Financeiro Nacional e a razão entre o capital social e o ativo da instituição, além dos indicadores relativos ao percentual entre as despesas de câmbio e as despesas operacionais existentes no Sistema Financeiro Nacional, considerado uma proxy da exposição cambial, percentual de empréstimos inadimplentes no Sistema e relação entre o Patrimônio Líquido e o Ativo Total do Sistema, considerados indicadores macroprudenciais dependentes de tomada de decisão por parte das instituições.

Para a estimação da máxima verossimilhança do modelo de fronteira estocástica, o conjunto de dados com as variáveis envolvidas foi criado na forma de painel não balanceado, como requerido pelo aplicativo Frontier, utilizado neste estudo.

O modelo a ser estimado, utilizando a função custo translog, é definido por

$$
\begin{aligned}
\ln \left(C_{i t}\right) & =\alpha_{0}+\sum_{j=1}^{3} \alpha_{j} \ln \left(y_{j i t}\right)+\beta_{1} \ln \left(p_{1 i t}\right)+\sum_{j=1}^{3} \gamma_{j} \ln \left(y_{j i t}\right) \ln \left(p_{1 i t}\right) \text { (9) } \\
& +\frac{1}{2} \sum_{j=1}^{3} \sum_{k=1}^{3} \alpha_{j k} \ln \left(y_{j i t}\right) \ln \left(y_{k i t}\right)+\frac{1}{2} \beta_{11} \ln \left(p_{1 i t}\right)^{2}+\tau_{1} T \\
& +\sum_{j=1}^{2} \theta_{j} \ln \left(x_{j i t}\right)+v_{i t}+u_{i t}
\end{aligned}
$$

onde:

$i$ indica a observação para a i-ésima instituição;

$t$ indica a observação no $t$-ésimo período; $C$ representa o custo total da instituição; $y_{1}$ representa o ativo líquido, calculado como sendo a soma das disponibilidades, aplicações interfinanceiras de liquidez, títulos e valores mobiliários e derivativos existentes nos balanços semestrais das instituições;

$y_{2}$ é o investimento, calculado como sendo a soma das relações interfinanceiras, interdependências, operações de arrendamento mercantil e outros créditos, valores e bens;

$y_{3}$ é o total dos depósitos;

$p_{1}$ é a razão entre o preço do capital e o preço dos depósitos, onde o preço do capital é calculado como sendo a proporção entre as despesas operacionais, exceto juros, e o ativo permanente e o preço dos depósitos é calculado como sendo a proporção entre as despesas com juros e o total dos depósitos;

$x_{1}$ é a taxa média de juros do semestre, representada pelo valor médio do C-Bond no período;

$x_{2}$ é a volatilidade média do índice da Bolsa de Valores de São Paulo; e

$T$ simboliza o tempo decorrido, sendo que 1 é o número atribuído ao $2^{\circ}$ semestre de 1995 , sendo acrescido de 1 unidade por semestre, até que 20 simboliza o $1^{\circ}$ semestre de 2005. 
Assumimos que os $v_{i t}$ são independentes e identicamente distribuídos como variáveis aleatórias normais, com média zero e variância $\sigma v 2$, independente dos $u_{i t}$.

Os $u_{i t}$ são ineficiências técnicas de custo não-negativas, assumidas como sendo independentemente distribuídas, tal que $u_{i t}$ é obtida pela truncagem (em zero) da distribuição $N\left(m_{i t}, \sigma^{2}\right)$, onde a média é definida por

$$
m_{i t}=\delta_{0}+\sum_{j=1}^{10} \delta_{j} z_{j i t}+\epsilon_{i t},
$$

onde:

$i$ indica a observação para a i-ésima instituição;

$t$ indica a observação no t-ésimo período;

$z_{1}, z_{2}, z_{3}$ e $z_{4}$ são variáveis do tipo dummy e representam, respectivamente, se a instituição é pública, estrangeira, com controle estrangeiro ou com participação estrangeira;

$z_{5}$ representa a razão entre a provisão efetuada pela instituição e os empréstimos totais ;

$z_{6}$ representa a participação da instituição no mercado, em relação aos depósitos totais;

$z_{7}$ é a razão entre o capital social e o ativo total;

$z_{8}$ é o percentual entre as despesas de câmbio e as despesas operacionais, existente no sistema financeiro nacional, sendo igual para todas as instituições no mesmo período;

$z_{9}$ é o percentual de empréstimos inadimplentes no sistema, sendo também igual para todas as instituições no mesmo período; e

$z_{10}$ é a relação entre a soma do Patrimônio Líquido das instituições e o Ativo Total do sistema. 
A tabela 1 nos mostra a média, desvio padrão e os valores máximos e mínimos das variáveis utilizadas na modelagem.

Tabela 1

Estatística descritiva

\begin{tabular}{lcccc}
\hline Variável & Média & Desvio Padrão & Mínimo & Máximo \\
\hline Ativo líquido $\left(y_{1}\right)^{* *}$ & 3.916 .563 & 12.416 .800 & 86 & 143.801 .600 \\
Investimento $\left(\mathrm{y}_{2}\right)^{* *}$ & 2.171 .359 & 8.524 .385 & 114 & 98.317 .556 \\
Depósitos $\left(\mathrm{y}_{3}\right)^{* *}$ & 3.758 .774 & 14.800 .189 & 2 & 146.040 .436 \\
Relação entre os preços $\left(p_{1}\right)^{*}$ & 24,68 & 227,33 & 0,0001 & 9.355 \\
Tempo $(T)$ & 9,49 & 5,68 & 1 & 20 \\
C-Bond $\left(x_{1}\right)$ & 819 & 381 & 381 & 1.883 \\
Ibovespa $\left(x_{2}\right)$ & 0,151 & 0,088 & 0,0879 & 0,314 \\
Provisão/Empréstimos $\left(z_{5}\right)$ & 0,05 & 0,09 & 0 & 0,999 \\
Part.Merc. depósitos $\left(z_{6}\right)$ & 0,0066 & 0,025 & $3 \times 10^{-9}$ & 0,23 \\
Capital/Ativos $\left(z_{7}\right)$ & 0,95 & 8,95 & $4 \times 10^{-9}$ & 364 \\
Desp.Câmbio/Desp.Oper. $\left(z_{8}\right)$ & 0,069 & 0,042 & 0,02 & 0,174 \\
Perc. Inadimplência $\left(z_{9}\right)$ & 0,055 & 0,025 & 0,018 & 0,089 \\
PL/Ativos do sistema $\left(z_{10}\right)$ & 0,079 & 0,013 & 0,052 & 0,096 \\
Custo total $(C)^{* *}$ & 7.010 .948 & 21.419 .888 & 1.316 & 326.717 .678 \\
\hline$z_{1}, z_{2}, z_{3}$ e $z_{4}$ são variáveis tipo dummy e representam a existência de bancos, respectivamente, \\
públicos $(27)$, estrangeiros $(14)$, com controle estrangeiro(56) e com participação estrangeira(17). \\
* Relação entre os preços é a relação entre o preço do capital e o preço dos depósitos, onde o \\
preço do capital é calculado como sendo a razão entre as despesas, exceto juros, e os ativos fixos \\
totais, e o preço dos depósitos é calculado como sendo a razão entre as despesas com juros e o \\
total dos depósitos. \\
** em R $\$$ mil.
\end{tabular}

\section{Resultados}

Primeiramente, a fronteira de custo foi estimada sem a presença das variáveis $x_{i}$, que representam indicadores macroprudenciais. Os coeficientes dessa estimação são mostrados na parte superior da tabela 2. 


\begin{tabular}{lcccc}
\hline Variável & Parâmetro & Coeficiente & Erro Padrão & Estatística $t$ \\
\hline Constante & $\alpha_{0}$ & $-0,240^{*}$ & 0,029 & $-8,222$ \\
$\ln \left(y_{1}\right)$ & $\alpha_{1}$ & $0,088^{*}$ & 0,048 & 1,837 \\
$\ln \left(y_{2}\right)$ & $\alpha_{2}$ & $-0,674^{*}$ & 0,068 & $-9,846$ \\
$\ln \left(y_{3}\right)$ & $\alpha_{3}$ & $2,714^{*}$ & 0,065 & 41,487 \\
$\ln \left(p_{1}\right)$ & $\beta_{1}$ & $0,014^{*}$ & 0,016 & 8,499 \\
$\ln \left(y_{1}\right) \ln \left(y_{2}\right)$ & $\alpha_{12}$ & 0,011 & 0,045 & 0,245 \\
$\ln \left(y_{1}\right) \ln (\mathrm{y} 3)$ & $\alpha_{13}$ & $-0,729^{*}$ & 0,055 & $-13,236$ \\
$\ln \left(y_{1}\right) \ln (\mathrm{p} 1)$ & $\gamma_{1}$ & $0,074^{*}$ & 0,022 & 3,266 \\
$\ln \left(y_{2}\right) \ln (\mathrm{y} 3)$ & $\alpha_{23}$ & $-0,223$ & 0,072 & $-3,089$ \\
$\ln \left(y_{2}\right) \ln (\mathrm{p} 1)$ & $\gamma_{2}$ & $0,436^{*}$ & 0,029 & 15,092 \\
$\ln \left(y_{3}\right) \ln (\mathrm{p} 1)$ & $\gamma_{3}$ & $-0,329^{*}$ & 0,03 & $-11,031$ \\
$\ln (\mathrm{y} 1) 2$ & $a_{11}$ & $0,121^{*}$ & 0,021 & 5,678 \\
$\ln \left(y_{2}\right) 2$ & $a_{22}$ & $0,200^{*}$ & 0,04 & 4,99 \\
$\ln \left(y_{3}\right) 2$ & $a_{33}$ & $0,450^{*}$ & 0,055 & 8,123 \\
$\ln \left(p_{1}\right) 2$ & $b_{11}$ & $-0,019^{*}$ & 0,002 & $-8,096$ \\
Tempo $(T)$ & $t_{1}$ & $-0,002^{*}$ & 0,0007 & $-2,528$ \\
\hline Constante & $\delta_{0}$ & $0,618^{* * *}$ & 0,474 & 1,303 \\
Público $\left(z_{1}\right)$ & $\delta_{1}$ & $1,024^{*}$ & 0,075 & 13,635 \\
Estrangeiro $\left(z_{2}\right)$ & $\delta_{2}$ & $-0,427^{*}$ & 0,077 & $-5,564$ \\
Controle Estrangeiro $\left(z_{3}\right)$ & $\delta_{3}$ & $-0,180^{*}$ & 0,072 & $-2,506$ \\
Participação Estrangeira $\left(z_{4}\right)$ & $\delta_{4}$ & $0,216^{*}$ & 0,112 & 1,931 \\
Provisão/Empréstimos $\left(z_{5}\right)$ & $\delta_{5}$ & $38,358^{*}$ & 1,803 & 21,277 \\
Part.Merc. Depósitos $\left(z_{6}\right)$ & $\delta_{6}$ & $-37,571^{*}$ & 1,687 & $-22,271$ \\
Capital/Ativos $\left(z_{7}\right)$ & $\delta_{7}$ & $3,468^{*}$ & 0,121 & 28,659 \\
Desp.Câmbio/Desp.Oper. $\left(z_{8}\right)$ & $\delta_{8}$ & $-17,592^{*}$ & 0,937 & $-18,778$ \\
Perc. Inadimplência $\left(z_{9}\right)$ & $\delta_{9}$ & $-2,399$ & 2,89 & $-0,83$ \\
PL/Ativos do sistema $\left(z_{10}\right)$ & $\delta_{10}$ & $-91,608^{*}$ & 5,439 & $-16,843$ \\
\hline$*, * *$ representam significância estatística ao nível de $1 \%$ e $5 \%$, respectivamente. & \\
( $)$ & & & &
\end{tabular}

Visto que o foco de nossa análise encontra-se na ineficiência e suas determinantes, nós não discutiremos os coeficientes de estimação da fronteira de custo detalhadamente. Entretanto, notamos que a grande maioria dos coeficientes estimados no modelo são altamente significantes.

Antes de discutirmos os parâmetros estimados da função de ineficiência e apresentar a ineficiência estimada, temos que verificar estatisticamente se há necessidade de utilização do modelo de fronteira estocástica e se os efeitos da ineficiência estão presentes na função de custo das instituições brasileiras. Isto pode ser feito, por meio de um teste de razão de verossimilhança para $\gamma=0\left(\gamma=\sigma^{2} / \sigma_{s}^{2}\right)$. Conforme descrito na tabela 5, o teste revelou uma estatística da ordem de 1.233 , bem superior aos valores apresentados por Kodde e Palm (1986). 
Posteriormente, foi estimada novamente a fronteira de custo, desta vez com a inclusão das variáveis $x_{1}$ e $x_{2}$ representando, respectivamente, a taxa média de juros do semestre e a volatilidade média do índice da Bolsa de Valores de São Paulo. Os coeficientes dessa nova estimação são mostrados na parte superior da tabela 3.

Tabela 3

Modelo 2: gerado com a inclusão das variáveis $x_{i}$ na função custo

\begin{tabular}{|c|c|c|c|c|}
\hline Variável & Parâmetro & Coeficiente & Erro Padrão & Estatística $t$ \\
\hline Constante & $\alpha_{0}$ & $-0,336^{*}$ & 0,074 & $-4,55$ \\
\hline $\ln \left(y_{1}\right)$ & $\alpha_{1}$ & $0,086^{* *}$ & 0,05 & 1,709 \\
\hline $\ln \left(y_{2}\right)$ & $\alpha_{2}$ & $-0,672^{*}$ & 0,07 & $-9,647$ \\
\hline $\ln \left(y_{3}\right)$ & $\alpha_{3}$ & $2,703^{*}$ & 0,068 & 39,945 \\
\hline $\ln \left(p_{1}\right)$ & $\beta_{1}$ & $0,142^{*}$ & 0,017 & 8,322 \\
\hline $\ln \left(y_{1}\right) \ln \left(y_{2}\right)$ & $\alpha_{12}$ & 0,015 & 0,047 & 0,319 \\
\hline $\ln \left(y_{1}\right) \ln \left(y_{3}\right)$ & $\alpha_{13}$ & $-0,737^{*}$ & 0,057 & $-12,798$ \\
\hline $\ln \left(y_{1}\right) \ln \left(p_{1}\right)$ & $\gamma_{1}$ & $0,076^{*}$ & 0,025 & 2,993 \\
\hline $\ln \left(y_{2}\right) \ln \left(y_{3}\right)$ & $\alpha_{23}$ & $-0,222^{*}$ & 0,072 & $-3,086$ \\
\hline $\ln \left(y_{2}\right) \ln \left(p_{1}\right)$ & $\gamma_{2}$ & 0,438 & 0,03 & 14,564 \\
\hline $\ln \left(y_{3}\right) \ln \left(p_{1}\right)$ & $\gamma_{3}$ & $-0,330 *$ & 0,032 & $-10,395$ \\
\hline $\ln \left(y_{1}\right)^{2}$ & $\alpha_{11}$ & $0,122^{*}$ & 0,022 & 5,529 \\
\hline $\ln \left(y_{2}\right)^{2}$ & $\alpha_{22}$ & $0,195^{*}$ & 0,041 & 4,705 \\
\hline $\ln \left(y_{3}\right)^{2}$ & $\alpha_{33}$ & $0,462 *$ & 0,056 & 8,258 \\
\hline $\ln \left(p_{1}\right)^{2}$ & $\beta_{11}$ & $-0,019^{*}$ & 0,002 & $-7,759$ \\
\hline Tempo (T) & $\tau_{1}$ & $-0,002^{*}$ & 0,0007 & $-3,411$ \\
\hline $\ln \left(x_{1}\right)$ & $\theta_{1}$ & $0,044 * *$ & 0,024 & 1,803 \\
\hline $\ln \left(x_{2}\right)$ & $\theta_{2}$ & $-0,379 * *$ & 0,183 & $-2,065$ \\
\hline Constante & $\delta_{0}$ & 0,007 & 0,467 & 0,014 \\
\hline Público $\left(z_{1}\right)$ & $\delta_{1}$ & $0,991 *$ & 0,076 & 13,057 \\
\hline Estrangeiro $\left(z_{2}\right)$ & $\delta_{2}$ & $-0,394 *$ & 0,132 & $-2,991$ \\
\hline Controle Estrangeiro $\left(z_{3}\right)$ & $\delta_{3}$ & $-0,204 *$ & 0,06 & $-3,415$ \\
\hline Participação Estrangeira $\left(z_{4}\right)$ & $\delta_{4}$ & $0,161^{* * * *}$ & 0,1 & 1,609 \\
\hline Provisão/Empréstimos $\left(z_{5}\right)$ & $\delta_{5}$ & $37,974 *$ & 1,734 & 21,895 \\
\hline Part.Merc. Depósitos $\left(z_{6}\right)$ & $\delta_{6}$ & $-37,137 *$ & 2,592 & $-14,327$ \\
\hline Capital/Ativos $\left(z_{7}\right)$ & $\delta_{7}$ & $3,214^{*}$ & 0,121 & 26,475 \\
\hline Desp.Câmbio/Desp.Oper. $\left(z_{8}\right)$ & $\delta_{8}$ & $-18,301^{*}$ & 0,807 & $-22,662$ \\
\hline Perc. Inadimplência $\left(z_{9}\right)$ & $\delta_{9}$ & $-7,895^{* *}$ & 4,677 & $-1,688$ \\
\hline PL/Ativos do sistema $\left(z_{10}\right)$ & $\delta_{10}$ & $-78,982 *$ & 7,012 & $-11,263$ \\
\hline
\end{tabular}

*, **, *** representam significância estatística ao nível de

$1 \%, 5 \%$ e $10 \%$, respectivamente.

Da mesma forma, o teste de razão de verossimilhança revelou uma estatística da ordem de 1.218, indicando presença de ineficiência.

Finalmente, foi estimada a fronteira de custo sem a inclusão das variáveis $x_{1} \mathrm{e}$ $x_{2}$, porém com a sua inclusão como determinantes da ineficiência. Os coeficientes dessa estimação final são mostrados na tabela 4, sendo que novamente o teste de razão de verossimilhança indicou presença de ineficiência, com uma estatística da ordem de 1.229. 
Tabela 4

Modelo 3: gerado com a inclusão das variáveis xi como determinante da eficiência

\begin{tabular}{|c|c|c|c|c|}
\hline Variável & Parâmetro & Coeficiente & Erro Padrão & Estatística $t$ \\
\hline Constante & $\alpha_{0}$ & $-0,218^{*}$ & 0,028 & 7,878 \\
\hline $\ln \left(y_{1}\right)$ & $\alpha_{1}$ & $0,096^{* *}$ & 0,049 & 1,965 \\
\hline $\ln \left(y_{2}\right)$ & $\alpha_{2}$ & $-0,670^{*}$ & 0,069 & $-9,661$ \\
\hline $\ln \left(y_{3}\right)$ & $\alpha_{3}$ & $2,627^{*}$ & 0,065 & 40,56 \\
\hline $\ln \left(p_{1}\right)$ & $\beta_{1}$ & $0,138^{*}$ & 0,016 & 8,38 \\
\hline $\ln \left(y_{1}\right) \ln \left(y_{2}\right)$ & $\alpha_{12}$ & 0,027 & 0,047 & 0,562 \\
\hline $\ln \left(y_{1}\right) \ln \left(y_{3}\right)$ & $\alpha_{13}$ & $-0,732 *$ & 0,058 & $-12,588$ \\
\hline $\ln \left(y_{1}\right) \ln \left(p_{1}\right)$ & $\gamma_{1}$ & $0,068^{*}$ & 0,024 & 2,803 \\
\hline $\ln \left(y_{2}\right) \ln \left(y_{3}\right)$ & $\alpha_{23}$ & $-0,237^{*}$ & 0,067 & $-3,523$ \\
\hline $\ln \left(y_{2}\right) \ln \left(p_{1}\right)$ & $\gamma_{2}$ & 0,448 & 0,028 & 15,824 \\
\hline $\ln \left(y_{3}\right) \ln \left(p_{1}\right)$ & $\gamma_{3}$ & $-0,312 *$ & 0,03 & $-10,503$ \\
\hline $\ln \left(y_{1}\right)^{2}$ & $\alpha_{11}$ & $0,117^{*}$ & 0,022 & 5,224 \\
\hline $\ln \left(y_{2}\right)^{2}$ & $\alpha_{22}$ & $0,188^{*}$ & 0,04 & 4,678 \\
\hline $\ln \left(y_{3}\right)^{2}$ & $\alpha_{33}$ & $0,501^{*}$ & 0,054 & 9,227 \\
\hline $\ln \left(p_{1}\right)^{2}$ & $\beta_{11}$ & $-0,020^{*}$ & 0,002 & $-8,209$ \\
\hline Tempo (T) & $\tau_{1}$ & $-0,001$ ** & 0,0008 & $-1,873$ \\
\hline Constante & $\delta_{0}$ & $-5,375^{*}$ & 0,527 & $-10,216$ \\
\hline $\ln \left(x_{1}\right)$ & $\theta_{1}$ & $1,721^{*}$ & 0,141 & 12,209 \\
\hline $\ln \left(x_{2}\right)$ & $\theta_{2}$ & $-16,714^{*}$ & 0,879 & $-19,015$ \\
\hline Público $\left(z_{1}\right)$ & $\delta_{1}$ & $0,818^{*}$ & 0,059 & 13,758 \\
\hline Estrangeiro $\left(z_{2}\right)$ & $\delta_{2}$ & $-0,376^{*}$ & 0,087 & $-4,298$ \\
\hline Controle Estrangeiro $\left(z_{3}\right)$ & $\delta_{3}$ & $-0,126^{*}$ & 0,054 & $-2,36$ \\
\hline Participação Estrangeira $\left(z_{4}\right)$ & $\delta_{4}$ & $0,268^{*}$ & 0,086 & 3,097 \\
\hline Provisão/Empréstimos $\left(z_{5}\right)$ & $\delta_{5}$ & $36,477 *$ & 1,187 & 30,728 \\
\hline Part.Merc. Depósitos $\left(z_{6}\right)$ & $\delta_{6}$ & $-34,203^{*}$ & 1,349 & $-25,355$ \\
\hline Capital/Ativos $\left(z_{7}\right)$ & $\delta_{7}$ & $3,336^{*}$ & 0,081 & 41,037 \\
\hline Desp.Câmbio/Desp.Oper. $\left(z_{8}\right)$ & $\delta_{8}$ & $-20,714^{*}$ & 0,645 & $-32,117$ \\
\hline Perc. Inadimplência $\left(z_{9}\right)$ & $\delta_{9}$ & $-24,976^{*}$ & 1,163 & $-21,466$ \\
\hline PL/Ativos do sistema $\left(z_{10}\right)$ & $\delta_{10}$ & $-41,452 *$ & 1,662 & $-24,94$ \\
\hline
\end{tabular}

Tabela 5

Estimativas da fronteira

\begin{tabular}{llccc}
\hline & & Modelo 1 & Modelo 2 & Modelo 3 \\
\hline Eficiência & Média & 0,834 & 0,834 & 0,84 \\
& Desvio Padrão & 0,134 & 0,133 & 0,132 \\
& Mínimo & 0,011 & 0,011 & 0,012 \\
& Máximo & 1,000 & 1,000 & 1,000 \\
& & & & \\
Descritivos & $\sigma_{v^{2}}$ & 0,002 & 0,017 & 0,017 \\
da fronteira & $\sigma_{u^{2}}$ & 0,121 & 1,215 & 0,969 \\
& $\lambda *$ & 7,781 & 8,454 & 7,55 \\
& $\gamma$ & 0,984 & 0,986 & 0,982 \\
& Log likelihood & 277,714 & 280,372 & 275,627 \\
& LR** & $1.233,823$ & $1.218,478$ & $1.229,648$ \\
\hline$*=$ u/ v. & & & &
\end{tabular}

** Testes de razão de verossimilhança generalizado para a hipótese $\gamma=0$

A rejeição dessa hipótese implica em que as ineficiências obtidas no modelo

são estatisticamente significantes. 
Verificamos que a inclusão de indicadores macroprudenciais ajusta melhor e aumenta a função custo do sistema bancário brasileiro, mostrando que as variáveis adicionadas (taxa média de juros do semestre e a volatilidade média do índice da Bolsa de Valores de São Paulo) melhoraram a estimativa do custo total das instituições. Além disso, o modelo melhora ainda mais quando essas variáveis são incluídas como determinantes da eficiência.

Dentre essas duas, ressalta-se a significância da taxa de juros. Essa variável, calculada como sendo a taxa média do C-Bond no período, significa a medição do risco país e o resultado nos mostra que se trata de um indicador a ser comumente avaliado pelos supervisores bancários, pois seu aumento implica num aumento de custo para as instituições, como verificado no modelo 2 , e numa perda de eficiência, como verificado no modelo 3.

Já a variável relativa à volatilidade do mercado acionário aparece na função custo como sendo um fator diminuidor de custo, como verificado no modelo 2 , e o aumento dessa volatilidade pode ser encarado como gerador de eficiência, de acordo com os resultados do modelo 3. Tal resultado pode ser explicado pelo fato de o índice da bolsa de valores de São Paulo, no período estudado, ter apresentado tendência de alta. Assim sendo, na média a volatilidade estaria indicando um aumento no valor das instituições.

No que diz respeito aos demais coeficientes encontrados na estimação da ineficiência, podemos verificar que são altamente significativos e, em todos os modelos, possuem os mesmos sinais.

Analisando a tabela 5, verificamos que a eficiência média desse modelo encontrada no período está em torno de $84,0 \%$, ou seja, em média, as instituições podem se tornar $16,0 \%$ mais eficientes.

Ainda examinando a tabela 5, o alto valor de $\lambda$ nos indica que uma boa parte do resíduo provém da ineficiência. Da mesma forma, analisando o valor de $\gamma$ chegamos à conclusão de que mais de $98,0 \%$ da variação residual é devida ao efeito ineficiência $u_{i}$, enquanto o erro aleatório $v_{i}$ não se mostra tão significante.

Passando ao comportamento da ineficiência, observamos a relação de determinantes de ineficiência, seus coeficientes, desvio padrão e estatística $t$.

A relação entre propriedade e ineficiência é determinada pelo grupo de dummies. Os coeficientes positivos encontrados para bancos públicos ou com alguma participação estrangeira, em conjunto com os coeficientes negativos para bancos estrangeiros ou com controle estrangeiros $\left(\delta_{1}\right.$ a $\left.\delta_{4}\right)$ deixam à mostra que no período os bancos privados sobrepujaram os públicos em eficiência, o mesmo acontecendo com os estrangeiros quando comparados aos nacionais.

\section{Conclusões}

Neste estudo foi mensurada e analisada a eficiência técnica das instituições financeiras no Brasil durante o período compreendido entre o segundo semestre de 1995 e o primeiro semestre de 2005, utilizando-se dados semestrais e estimando-se a fronteira estocástica de custo. 
Foi calculada a eficiência das instituições e investigada a relação existente entre essa eficiência e algumas variáveis micro e macroprudenciais. A média das eficiências técnicas foi sempre superior a 0,83 . Foram encontrados indícios de ineficiência no setor bancário brasileiro e ela tem se apresentado de forma quase cíclica, com aumento em 1996, 1999 e 2002.

Verificamos que o C-Bond está correlacionado com o aumento do custo das instituições financeiras e com a queda da eficiência, enquanto o Ibovespa está correlacionado com a diminuição daquele custo e com maior eficiência.

Outros indicadores macroprudenciais incluídos no modelo nos revelaram que a diminuição do Patrimônio Líquido das instituições pode também ser considerado um ponto de alerta do sistema.

A análise da eficiência calculada nos modelos da fronteira estocástica de custo nos revela, ainda, alguns outros aspectos muito contemplados na literatura.

Ao nível gerencial, encontramos maior eficiência das instituições estrangeiras e privadas.

Os aumentos da provisão para contemplar perdas com os empréstimos concedidos mostraram correlação com ineficiência, enquanto foi percebido aumento da eficiência nos bancos com maior concentração de depósitos.

Cabe ressaltar, ainda, que efetuamos várias análises e identificamos alguns pontos a favor e outros contrários a estudos anteriores, porém, existem muitas outras variáveis a se testar quanto a sua influência na eficiência bancária.

Finalmente, um ponto que nos pareceu por demais importante em nosso estudo foi a relevância dos indicadores macroprudenciais incluídos tanto na estimação da fronteira de custo quanto na equação de eficiência, ficando caracterizada a necessidade de acompanhamento desses índices no futuro, bem como comprovando a influência que esses indicadores exercem na eficiência bancária.

\section{Referências}

Aigner, D. J. \& Chu, S. F. (1968). On estimating the industry production function. American Economic Review, 58:826-839.

Aigner, D. J., Lovell, C. A. K., \& Schmidt, P. (1977). Formulation and estimation of sthocastic frontier production function models. Journal of Econometrics, 6:21-37.

Akhigbe, A. \& McNulty, J. E. (2006). Bank monitoring and profit efficiency.

Allen, L. \& Rai, A. (2000). Operational efficiency in banking: An international comparison. Journal of Banking and Finance, 20:655-672.

Altunbas, Y., Evans, L., \& Molyneux, P. (2001a). Bank ownership and efficiency. Journal of Money, Credit and Banking, 33:926-954.

Altunbas, Y., Gardener, E. P. M., Molyneux, P., \& Moore, B. (2001b). Efficiency in european banking. European Economic Review, 45:1931-1955. 
Altunbas, Y., Liu, M. H., Molyneux, P., \& Seth, R. (2000). Efficiency and risk in Japanese banking. Journal of Banking and Finance, 24:1605-1628.

Barajas, A., Steiner, R., \& Salazar, N. (2000). The impact of liberalization and foreign investment in Colombia's financial sector. Journal of Development Economics, 63:157-196.

Battese, G. E. \& Coelli, T. J. (1993). A stochastic frontier production function incorporating a model for technical inefficiency effects. Working Papers in Econometrics and Applied Statistics, 69.

Battese, G. E. \& Coelli, T. J. (1995). A model for technical inefficiency effects in a stochastic frontier production function for panel data. Empirical Economics, 20:325-332.

Beck, T., Crivelli, J. M., \& Summerhill, W. (2005). State bank transformation in Brazil - choices and consequences. Journal of Banking and Finance, 29:22232257.

Berg, S. A., Forsend, F. R., Hjalmarsson, L., \& Suominen, M. (1993). Banking efficiency in the Nordic countries. Journal of Banking and Finance, 17:371388 .

Berger, A. N., DeYoung, R., Genay, H., \& Udell, G. F. (2000). Globalization of financial institutions: Evidence from cross-border banking performance. Brookings-Wharton Papers on Financial Services, 3.

Berger, A. N. \& Humphrey, D. B. (1992). Measurement and Efficiency Issues in Commercial Banking. NBER, University of Chicago Press, Chicago.

Berger, A. N. \& Humphrey, D. B. (1997). Efficiency of financial institutions: International survey and directions for future research. European Journal of Operational Research, 98:175-212.

Berger, A. N. \& Mester, L. J. (1997). Inside the black box: Whal explains differences in the efficiencies of financial institutions? Journal of Banking and Finance, 21:895-947.

Bonin, J. P., Hasan, I., \& Wachtel, P. (2005). Privatization matters: Bank efficiency in transition countries. Journal of Banking and Finance, 29:2155-2178.

Bos, J. W. B. \& Kool, C. J. M. (2001). Bank Size, Specialization and Efficiency in the Netherlands: 1992-1998. Meteor Research Memorandum, Maastricht University. RM/01/018.

Bos, J. W. B. \& Kool, C. J. M. (2006). Bank efficiency: The role of bank strategy and local market conditions. Journal of Banking and Finance, 30:1953-1974. 
Canhoto, A. \& Dermine, J. (2003). A note on banking efficiency in Portugal, new vs. old banks. Journal of Banking and Finance, 27:2087-2098.

Carson, C. S. \& Ingves, S. (2001). Financial Soundness Indicators: Policy Paper. International Monetary Fund.

Carvallo, O. \& Kasman, A. (2005). Cost efficiency in the Latin American and Caribbean banking systems. International Financial Markets, Institutions and Money, 15:55-72.

Chang, C. E., Hasan, I., \& Hunter, W. C. (1998). Efficiency of multinational banks: An empirical investigation. Applied Financial Economics, 8:1-8.

Christopoulos, D. K., Lolos, S. E. G., \& Tsionas, E. G. (2002). Efficiency of the Greek banking system in view of the EMU: A heteroscedastic stochastic frontier approach. Journal of Policy Modeling, 24:813-829.

Claessens, S., Demirgüç-Kunt, A., \& Huizinga, H. (2001). How does foreign entry affect domestic banking markets? Journal of Banking and Finance, 25:891911.

Coelli, T., Rao, D. S. P., \& Battese, G. E. (1998). An Introduction to Efficiency and Productivity Analysis. Kluwer Academic Publishers.

Crystal, J. B., Dages, G., \& Goldberg, L. (2001). Does foreign ownership contribute to sounder banks in emerging markets? The Latin America experience. Federal Reserve Bank of New York Staff Reports, 137.

DeYoung, R. \& Nolle, D. E. (1996). Foreign-owned banks in the United States: Earning market share or buying it? Journal of Money, Credit and Banking, 28(4):622-636.

Dietsch, M. \& Lozano-Vivas, A. (2000). How the environment determines banking efficiency: A comparison between French and Spanish industries. Journal of Banking and Finance, 24:985-1004.

Drake, L. \& Hall, M. J. B. (2003). Efficiency in Japanese banking. Journal of Banking and Finance, 27:891-917.

Estrada, D. \& Osorio, P. (2004). Effects of financial capital on colombian banking efficiency. In Borradores de Economia. Banco de La República. 001741.

Farrell, M. J. (1957). The mesasurement of productive efficiency. Journal of the Royal Statistical Society, CXX(3):253-290.

Fecher, F. \& Pestieau, P. (1993). Efficiency and competition in O.E.C.D. financial services. In Fried, H. O., Lovell, C. A. K., \& Schmidt, S. S., editors, The Measurement of Productive Efficiency: Techniques and Applications, pages 374-385. Oxford University Press, UK. 
Grifell-Tatjé, E. \& Lovell, C. A. K. (1995). A note on the Malmquist productivity index. Economics Letters, 47:169-175.

Halkos, G. E. \& Salamouris, D. S. (2004). Efficiency measurement of the Greek commercial banks with the use of financial ratios: A data development anlysis approach. Management Accounting Research, 15:201-224.

Hasan, I. \& Hunter, W. C. (1996). Efficiency of Japanese multinational banks in the United States. Research in Finance, 14:157-173.

Havrylchyk, O. (2006). Efficiency of the polish banking industry: Foreign versus domestic banks. Journal of Banking and Finance, 30:1975-1996.

Huang, C. J. \& Liu, J. T. (1994). Estimation of a non-neutral stochastic frontier production function. Journal of productivity analysis, 5:171-180.

Hughes, J., Mester, L., \& Moon, C. (2000). Are scales economies in banking elusive or illusive? Evidence obtained by incorporating capital structure and risktaking into models of bank production. Federal Reserve Bank of Philadelphia, Economic Research Division, Working Paper, n. 00-04.

Hughes, J. P., Lang, W., Mester, L. J., \& Moon, C. G. (1996). Efficient banking under interstate branching. Journal of Money, Credit and Banking, 28(4):10451071. parte 2 .

Jondrow, J., Lovell, C. A. K., Materov, I. S., \& Schmidt, P. (1982). On the estimation of technical inefficiency in the stochastic frontier production function model. Journal of Econometrics, 19:233-238.

Kalirajan, K. P. (1981). An econometric analysis of yield variability in paddy production. Canadian Journal of Agricultural Economics, 29:283-294.

Kodde, D. A. \& Palm, F. C. (1986). Wald criteria for jointly testing equality and inequality restrictions. Econometrica, 54:1243-1248.

Krause, K. \& Tabak, B. M. (2004). Eficiência bancária: Uma aplicação DEA para os segmentos bancários no Brasil. Relatório de Estabilidade Financeira, Brasília, Banco Central do Brasil.

Kumbhakar, S. C., Ghosh, S., \& McGuckin, J. T. (1991). A generalized production frontier approach for estimating determinants of inefficiency in U.S. dairy farms. Journal of Business and Economic Statistics, 9:279-286.

Kwan, S. H. (2001). The X-efficiency of commercial banks in Hong-Kong. Federal Reserve Bank of San Francisco. Working Papers in Applied Economic Theory, n. 2002-14. 
Levinsohn, J. \& Petrin, A. (2003). Estimating production functions using inputs to control for unobservables. Review of Economic Studies, 70:317-342.

Mahajan, A., Rangan, N., \& Zardkoohi, A. (1996). Cost structures in multinational and domestic banking. Journal of Banking and Finance, 20:283-306.

Maudos, J., Pastor, J. M., Pérez, F., \& Quesada, J. (2002). Cost and profit efficiency in European banks. Journal of International Financial Makets, Institutions and Money, 12:33-58.

Meeusen, W. \& Van Den Broeck, J. (1977). Efficiency estimation from CobbDouglas production functions with composed error. International Economic Review, 18:435-444.

Morales, R. A. \& Schumacher, L. (2003). Market volatility as a financial soundness indicator: An application to Israel. IMF Working Paper.

Nakane, M. (1999). Productive efficiency in Brazilian banking sector. Texto para discussão 20-99, São Paulo: IPE/USP.

Nakane, M. I. \& Weintraub, D. B. (2005). Bank privatization and productivity: Evidence for Brazil. Journal of Banking and Finance, 29:2259-2289.

Pastor, J. M., Pérez, F., \& Quesada, J. (1997). Efficiency analysis in banking firms: An international comparison. European Journal of Operational Research, 98:395-407.

Peek, J., Rosengren, E. S., \& Kasirye, F. (1999). The poor performance of foreign bank subsidiaries: Were the problems acquired or created? Journal of Banking and Finance, 22:799-819.

Pitt, M. M. \& Lee, L. F. (1981). Measurement and sources of technical inefficiency in the Indonesian weaving industry. Journal of Development Economics, 9:4364.

Prior, D. (2003). Long and short-run non-parametric cost frontier efficiency: An application to Spanish saving banks. Journal of Banking and Finance, 27:655671.

Reifschneider, D. \& Stevenson, R. (1991). Systematic departures from the frontier: A framework for the analysis of firm inefficiency. International Economic Review, 32:715-723.

Ruthenberg, D. \& Elias, R. (1996). Cost economies and interest rate margins in a unified European banking market. Journal of Economics and Business, 48:231249. 
Schure, P., Wagenvoort, R., \& O'Brien, D. (2004). The efficiency an the conduct of European banks: Development after 1992. Review of Financial Economics, 13:371-396.

Sensarma, R. (2006). Are foreign banks always the best? Comparison of stateowned, private and foreign banks in India, 23:717-735.

Sheldon, G. (1999). Costs, competitiveness and the changing structure of European banking. Fondation Banque de France pour la Recherche, working paper.

Silva, T. L. \& Jorge Neto, P. M. (2002). Economia de escala e eficiência nos bancos brasileiros após o Plano Real. Estudos Econômicos, 32(4):577-619.

Sturm, J. E. \& Williams, B. (2004). Foreign bank entry, deregulation and bank efficiency: Lessons from the Australian experience. Journal of Banking and Finance, 28:1775-1799.

Yildrin, H. S. \& Philippatos, G. C. (2002). Efficiency of banks: Recent evidence from the transition economies of Europe: 1993-2000. University of Saskatchewan Working Paper. 


\section{Apêndice}

Para complemento do artigo foram estimados modelos com a utilização da função Cobb-Douglas, sendo a fronteira estocástica de custo definida por

$$
\ln \left(C_{i t}\right)=\alpha_{0}+\sum_{j=1}^{3} \alpha_{j} \ln \left(y_{j i t}\right)+\beta_{1} \ln \left(p_{1 i t}\right)+\tau_{1} T+\sum_{j=1}^{2} \theta_{j} x_{j i t}+v_{i t}+u_{i t}
$$

onde os índices possuem o mesmo significado adotado no capítulo 4.

Os modelos gerados estão apresentados nas tabelas A.1 e A.2 e as estimativas da fronteira, na tabela A.3.

Utilizando-se o teste de razão de verossimilhança generalizado, testamos a hipótese nula de que esses modelos (Cobb-Douglas) representam adequadamente os dados, dadas as especificações dos modelos resultantes da utilização da função translog, da seguinte forma:

$$
\text { Modelo 1: } \mathrm{LR}=-2(542,090-705,155)=326,13
$$

Modelo 2: $\mathrm{LR}=-2(556,754-721,474)=329,44$

Como esses valores de LR são bastante significantes, rejeitamos a hipótese nula e chegamos à conclusão de que os modelos resultantes da utilização da função translog são preferíveis aos modelos resultantes da utilização da função CobbDouglas.

Tabela A.1

Modelo 1 gerado com a utilização da função Cobb-Douglas

\begin{tabular}{lcccc}
\hline Variável & Parâmetro & Coeficiente & Erro Padrão & Estatística $t$ \\
\hline Constante & $\alpha_{0}$ & $-0,020^{*}$ & 0,012 & $-1,641$ \\
$\ln \left(y_{1}\right)$ & $\alpha_{1}$ & $0,369^{*}$ & 0,013 & 26,885 \\
$\ln \left(y_{2}\right)$ & $\alpha_{2}$ & $0,372^{*}$ & 0,018 & 20,232 \\
$\ln \left(y_{3}\right)$ & $\alpha_{3}$ & $0,155^{*}$ & 0,021 & 7,264 \\
$\ln \left(p_{1}\right)$ & $\beta_{1}$ & $-0,024^{*}$ & 0,003 & $-6,675$ \\
Tempo $(\mathrm{T})$ & $\theta_{1}$ & $0,007^{*}$ & 0,0005 & 13,327 \\
\hline Constante & $\delta_{0}$ & $8,479^{*}$ & 2,521 & 3,362 \\
Público $\left(z_{1}\right)$ & $\delta_{1}$ & $-0,880^{*}$ & 0,152 & $-5,774$ \\
Estrangeiro $\left(z_{2}\right)$ & $\delta_{2}$ & $0,929^{*}$ & 0,132 & 7,013 \\
Controle Estrangeiro $\left(z_{3}\right)$ & $\delta_{3}$ & $1,119^{*}$ & 0,152 & 7,339 \\
Participação Estrangeira $\left(z_{4}\right)$ & $\delta_{4}$ & $0,728^{*}$ & 0,121 & 5,991 \\
Provisão/Empréstimos $\left(z_{5}\right)$ & $\delta_{5}$ & $13,980^{*}$ & 1,677 & 8,333 \\
Part.Merc. Depósitos $\left(z_{6}\right)$ & $\delta_{6}$ & $-40,146^{*}$ & 9,473 & $-4,237$ \\
Capital/Ativos $\left(z_{7}\right)$ & $\delta_{7}$ & $1,348^{*}$ & 0,152 & 8,837 \\
Desp.Câmbio/Desp.Oper. $\left(z_{8}\right)$ & $\delta_{8}$ & $10,183^{*}$ & 1,678 & 6,067 \\
Perc. Inadimplência $\left(z_{9}\right)$ & $\delta_{9}$ & $6,812^{*}$ & 2,244 & 3,034 \\
PL/Ativos do sistema $\left(z_{10}\right)$ & $\delta_{10}$ & $-59,288^{*}$ & 10,013 & $-5,92$ \\
\hline * representa significância & estat́stín
\end{tabular}

* representa significância estatística ao nível de $1 \%$. 
Ruiz, C., Tabak, B., Cajueiro, D.

Tabela A.2

Modelo 2: gerado com a utilização da função Cobb-Douglas e inclusão das variáveis $x_{i}$

\begin{tabular}{lcccc}
\hline Variável & Parâmetro & Coeficiente & Erro Padrão & Estatística $t$ \\
\hline Constante & $\mathrm{a} 0$ & $-0,291^{*}$ & 0,067 & $-4,284$ \\
$\ln \left(y_{1}\right)$ & $\alpha_{1}$ & $0,378^{*}$ & 0,014 & 25,517 \\
$\ln \left(y_{2}\right)$ & $\alpha_{2}$ & $0,382^{*}$ & 0,018 & 20,675 \\
$\ln \left(y_{3}\right)$ & $\alpha_{3}$ & $0,138^{*}$ & 0,021 & 6,481 \\
$\ln \left(p_{1}\right)$ & $\beta_{1}$ & $-0,026^{*}$ & 0,002 & $-8,891$ \\
Tempo $(\mathrm{T})$ & $\theta_{1}$ & $0,008^{*}$ & 0,0007 & 12,012 \\
\hline $\ln \left(x_{1}\right)$ & $\theta_{1}$ & $0,086^{*}$ & 0,023 & 3,661 \\
$\ln \left(x_{2}\right)$ & $\theta_{2}$ & $0,304^{* *}$ & 0,151 & 2,012 \\
Constante & $\delta_{0}$ & $9,615^{*}$ & 2,412 & 3,985 \\
Público $\left(z_{1}\right)$ & $\delta_{1}$ & $-0,761^{*}$ & 0,119 & $-6,398$ \\
Estrangeiro $\left(z_{2}\right)$ & $\delta_{2}$ & $0,821^{*}$ & 0,111 & 7,361 \\
Controle Estrangeiro $\left(z_{3}\right)$ & $\delta_{3}$ & $1,042^{*}$ & 0,127 & 8,156 \\
Participação Estrangeira $\left(z_{4}\right)$ & $\delta_{4}$ & $0,688^{*}$ & 0,101 & 6,756 \\
Provisão/Empréstimos $\left(z_{5}\right)$ & $\delta_{5}$ & $13,220^{*}$ & 1,51 & 8,751 \\
Part.Merc. Depósitos $\left(z_{6}\right)$ & $\delta_{6}$ & $-43,382^{*}$ & 9,133 & $-4,749$ \\
Capital/Ativos $\left(z_{7}\right)$ & $\delta_{7}$ & $1,381^{*}$ & 0,147 & 9,379 \\
Desp.Câmbio/Desp.Oper. $\left(z_{8}\right)$ & $\delta_{8}$ & $7,071^{*}$ & 1,281 & 5,517 \\
Perc. Inadimplência $\left(z_{9}\right)$ & $\delta_{9}$ & $4,590^{*}$ & 1,535 & 2,988 \\
PL/Ativos do sistema $\left(z_{10}\right)$ & $\delta_{10}$ & $-51,566^{*}$ & 7,609 & $-6,776$ \\
\hline
\end{tabular}

* representa significância estatística ao nível de $1 \%$.

Tabela A.3

Estimativas da fronteira

\begin{tabular}{cccc}
\hline & & Modelo 1 & Modelo 2 \\
\hline Eficiência & Média & 0,812 & 0,814 \\
& Desvio Padrão & 0,153 & 0,151 \\
& Mínimo & 0,137 & 0,143 \\
& Máximo & 0,982 & 0,982 \\
Descritivos & & & \\
da fronteira & $\sigma_{v^{2}}$ & 0,008 & 0,008 \\
& $\sigma_{u^{2}}$ & 0,538 & 0,49 \\
& $\lambda *$ & 8,236 & 7,865 \\
& $\gamma$ & 0,985 & 0,983 \\
& Log likelihood & 542,09 & 556,75 \\
& LR** & $1.098,58$ & $1.002,12$ \\
\hline$*$
\end{tabular}

$*^{*} \gamma=\sigma_{u} / \sigma_{v}$

** Testes de razão de verossimilhança generalizado para a

hipótese $\gamma=0$. A rejeição dessa hipótese implica em que

as ineficiências obtidas no modelo são estatisticamente significantes. 